\title{
Treatment of Dopaminomimetic Psychosis in Parkinson's Disease with Electroconvulsive Therapy
}

\author{
T.A. Hurwitz, D.B. Calne and K. Waterman
}

\begin{abstract}
Two Parkinsonian patients with chronic nonconfusional dopaminomimetic psychosis were treated with a course of electroconvulsive therapy. In both cases sustained remission of psychosis was obtained in the face of ongoing administration of dopaminomimetics.
\end{abstract}

\begin{abstract}
RÉSUMÉ: Traitement de la psychose dopaminomimétique par sismothérapie dans la maladie de Parkinson. Deux patients parkinsoniens, atteints de psychose dopaminomimétique chronique sans confusion, ont été traités par sismothérapie. Dans les deux cas, une rémission prolongée a été obtenue malgré le maintien de la thérapie dopaminomimétique.
\end{abstract}

Can. J. Neurol. Sci. 1988; 15:32-34

Longterm levodopa or bromocriptine therapy in patients with Parkinson's Disease may produce a variety of disabling psychiatric syndromes which includes restless agitation, hypomania, anxiety, hypersexual behaviour, and psychosis. 1.2,3.4.5 A psychosis may occur in the presence or absence of confusion and usually responds to a dose reduction or drug withdrawal. ${ }^{3}$ In some patients this will lead to life threatening immobility. Any attempt to restart dopaminomimetics may lead to a recurrence of symptoms. The clinician is left with the unenviable choice of maintaining a patient mobile and mad or sane but unable to move. ${ }^{6}$ Neuroleptics may be administered but their dopamine blocking properties lead to deterioration in motor function. Electroconvulsive therapy (ECT) is of potential benefit in these circumstances since it has proven efficacy in other psychoses and has been shown to decrease some cases of Parkinsonian disability. $7,8,9,10$

\section{MeThod}

Two patients with chronic nonconfusional dopaminomimetic psychosis were treated with a course of bilateral ECT after informed written consent was obtained from the patients and their families. The protocol had been approved by the University and Hospital Ethics Committees. Both patients were receiving dopaminomimetic drugs but no other antiparkinsonian medication. They had been psychotic for several months despite repeated attempts to lower their dose of dopaminomimetics. They were rated weekly on the Columbia Scale for Parkinsonian Disability (higher scores indicating increasing disability), the Brief Psychiatric Rating Scale with the item for motor retardation eliminated (higher scores indicating increasing mental disturbance), and the Mini-Mental State (higher scores indicating normal intellectual function with a maximum score of 30 ). Assessments were performed prior to, during and subsequent to the course of ECT. ${ }^{11,12,13}$ Over the period of ECT the dose of dopaminomimetics was kept constant. Following ECT the doses of medications were raised to optimize mobility.

\section{Case Reports}

Case 1. A woman aged 66 years, with a seventeen year history of Parkinson's disease (Hoehn and Yahr Stage V) presented with a seven month history of a paranoid and depressive psychosis. ${ }^{14}$ She had been on Sinemet for the preceding twelve years and was on Sinemet and bromocriptine at the time of admission. She had no previous psychiatric illness but had a positive family history for psychiatric disorder. Her psychosis was characterized by persistent, mood incongruent auditory hallucinations, occasional visual and somatic hallucinations, visual illusions, delusions of guilt, and delusions of reference and control. These phenomena occurred in the setting of depression, intermittent severe anxiety, obsessional ideas about sex, anergy, weeping, moderate hopelessness and global insomnia. Bedside evaluation of higher intellectual functions were within normal limits and her Mini-Mental State score was twenty-nine. She was wheelchair bound because of bilateral hip and leg contractures. Her initial Columbia score was $\mathbf{4 0 .}$ 


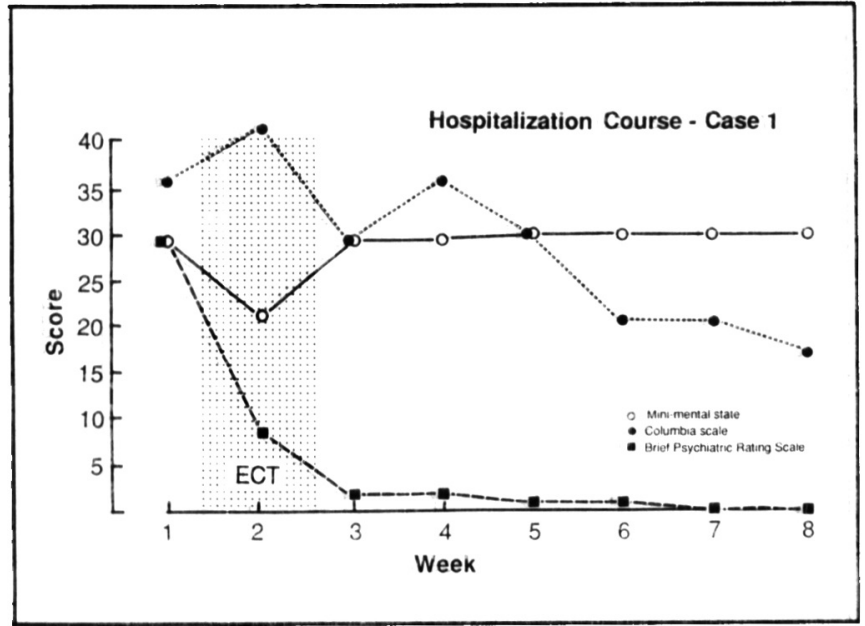

Figure I Hospitalization Course - Case I

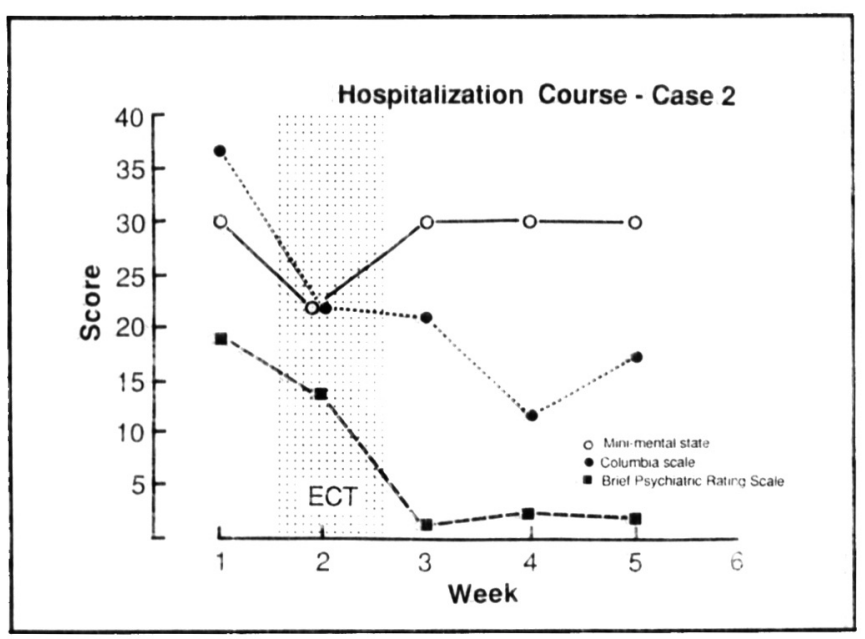

Figure 2 Hospitalization Course - Case 2

Prior to and during ECT she was on Sinemet $50 / 500 \mathrm{mg}$ per day and bromocriptine $7.5 \mathrm{mg}$ a day. She was given six bilateral ECT with a total seizure time of 200 seconds. ECT produced a transient delirium attended by a fall in the Mini-Mental State score to twenty-one. The delirium cleared rapidly leaving a normal mental state. Over the next six weeks the total daily dose of Sinemet was increased to $125 / 1,250$ $\mathrm{mg}$. The dose of bromocriptine was unchanged. This led to an increase in mobility without recurrence of psychosis. Despite the resolution of psychosis, global insomnia remained and was successfully treated with oxazepam $120 \mathrm{mg}$ at night. Her seven week course in hospital is detailed in Figure 1. After eight weeks she was transferred to a rehabilitation hospital for management of her contractures. At three month follow-up she remained free of psychosis except for an isolated episode of auditory hallucinations. At six month follow-up she was again free of psychosis but had occasional visual illusions and nightmares.

Case 2. A man aged 60 years, with a six year history of Parkinson's disease (Hoehn and Yahr Stage III) presented with paranoid psychosis of four months duration. He had been on Sinemet for six years. He had no previous psychiatric illness and no family history of psychiatric disorder. His psychosis was characterized by global insomnia, thought broadcast, and florid, unsystematized, bizarre, paranoid and grandiose delusions that would change from day to day. The delusions were based upon thought insertion and mood incongruent auditory hallucinations. Bedside evaluation of higher intellectual functions were within normal limits and the Mini-Mental State score was thirty. The initial Columbia Scale score was thirty-seven. Prior to and during ECT he was maintained on $112.5 / 450 \mathrm{mg}$ Sinemet per day. He was given three bilateral ECT with a total seizure time of 155 seconds. ECT produced a florid delirium attended by a drop in his Mini-Mental State score. The de- lirium cleared over one week leaving a normal mentai state. Two weeks later the total daily dose of Sinement was raised to $75 / 750 \mathrm{mg}$ a day with an increase in his mobility and no recurrence of psychosis. Insomnia persisted and was successfully treated with oxazepam $75 \mathrm{mg}$ at night. He was discharged to live with his wife after five weeks in hospital. At five month follow-up he was functioning independently with a normal mental state. His course is detailed in Figure 2.

\section{Discussion}

Nonconfusional dopaminomimetic psychosis usually occurs after longterm dopaminomimetic therapy although it may present within a few weeks of starting treatment in patients with pre-existing psychiatric disorders. ${ }^{5}$ Approximately $3 \%$ of patients treated with I-dopa for more than two years will develop this complication. ${ }^{3.5}$ The most common presentation is a paranoid psychosis. 'The psychosis usually evolves out of a background of sleep disruption, vivid dreams and haliucinations "It may. ultimately progress to a confusional psychosis although confusion is more likely to occur in patients with some pre-existing impairment of intellectual function. . $^{3,16}$

Levodopa psychosis has been attributed to dopamine induced alterations in central serotonin activity. ${ }^{17.18 .19}$ In patients dying with l-dopa psychosis, elevated levels of serotonin have been reported predominantly in the red nucleus but also in the raphe nuclei and the globus pallidus. ${ }^{17}$ Elevated levels may be due to displacement of serotonin from serotonergic neurons by l-dopa: this would alter the dopamine/serotonin balance and and perhaps trigger the psychosis. ${ }^{17}$ However drugs that increase or decrease serotonergic transmission do not have any consistent effect on 1-dopa psychosis. ${ }^{19.20} \mathrm{~L}$-dopa psychosis has also been attributed to agonist induced hypersensitivity of the postsynaptic dopamine receptors. ${ }^{21}$ Chronic stimulation of dopamine receptor sites has been claimed to induce supersensitivity of the postsynaptic dopamine receptors in rats and guinea pigs as shown by a decrease in the threshold and latency' of onset of stereotypic behaviours to apomorphine (a direct dopaminomimetic) and d-amphetamine (an indirect dopaminomimetic). 22.23.24 Similar 'innervation' induced dopamine receptor hypersensitivity has been reported for bromocriptine. 25 Postsynaptic receptor hypersensitivity has also been postulated to be responsible for dopaminomimetic dyskinesias which, like the psychosis, occurs after longterm treatment. Indeed, dyskinesias and psychosis frequently co-exist. ${ }^{24}$ In psychosis. hypersensitivity may involve the mesolimbic dopamine projection. This mechanism is supported by the beneficial effect of clozapine and fluperlapine in dopaminomimetic psychosis. Both these drugs are D2 blocking agents that preferentially bind to mesolimbic, mesocortical and hippocampal D2 receptors with no substantial binding to striatal dopamine receptors. ${ }^{26.27}$ The use of clozapine and fluperlapine in dopaminomimetic psychosis is limited because of the risk of agranulocytosis. ${ }^{28}$

The central importance of dopaminomimetics agents for the development of the psychosis is undoubted. Withdrawal or dose reduction will often allow the psychosis to remit. ${ }^{3}$ It is also possible to treat the psychosis with neuroleptics at the risk of exacerbating the underlying Parkinsonian disability. In our two cases restitution to a normal mental state by a course of ECT was sustained over several months in the face of an increased dose of dopaminomimetics. Thus dopaminomimetic psychosis may be due to a functional alteration in dopamine receptors that is reversible by ECT.

The effect of ECT on dopamine receptors is controversial. Modigh et al have recently reviewed all the in vivo animal data and conclude that ECT increases the responsiveness of the postsynaptic dopamine receptors whereas the responsiveness of the presynaptic dopamine receptors is decreased. ${ }^{29}$ They and others have shown that ECT may improve Parkinsonian disabil- 
ity suggesting that ECT enhances postsynaptic dopamine receptor responsiveness. ${ }^{7,8,9,10,29,30,31}$ This benefit was not however, confirmed by Ward et al. ${ }^{32}$ Moreover in rats, ECT prevents haloperidol induced dopamine receptor hypersensitivity. ${ }^{33}$ These conflicting data are difficult to reconcile with our observations and raise the possibility that, in dopaminomimetic psychosis, ECT may be producing its effect via non-dopaminergic mechanisms.

Although our experience is limited to two patients, we consider that ECT may be a useful treatment in dopaminomimetic psychosis. Further study of ECT in dopaminomimetic psychosis is desirable to extend these preliminary observations.

\section{REFERENCES}

1. Goodwin FK. Behavioural effects of 1-dopa in man. Semin Psychiatry 1971: 3: 477-492.

2. Damasio AR, Lobo-Antunes J, Macedo C. Psychiatric aspects in parkinsonism treated with l-dopa. J Neurol Neurosurg Psychiatry 1971; 34: 502-507.

3. Celesia GC, Barr AN. Psychosis and other psychiatric manifestations of levodopa therapy. Arch Neurol 1970; 23: 193-200.

4. Parkes JD. Adverse effects of antiparkinsonian drugs. Drugs 1981; 21: $341-353$.

5. Klawans HL. What to do when sinemet fails: Part one. Clin Neuropharmacol 1984; 7: 121-133.

6. Marsden CD, Fahn S. Problems in Parkinson's disease. In: Marsden CD, Fahn S, eds. Movement Disorders. London: Butterworth Scientific 1982;1-7.

7. Lebensohn $\mathrm{ZM}$, Jenkins $\mathrm{RB}$, Improvement of parkinsonism in depressed patients treated with ECT. Am J Psychiatry 1975; 132: 283-285.

8. Asnis G. Parkinson's disease, depression and ECT: A review and case study. Am J Psychiatry 1977; 134: 191-195.

9. Levy L, Savit JM, Hodes M. Parkinsonism: Improvement by electroconvulsive therapy. Arch Phys Med Rehabil 1983; 64: 432-433.

10. Lipper S, Bermanzohn PC. Electroconvulsive therapy in patients with parkinsonism. Am J Psychiatry 1975; 132:457.

11. Duvoisin RC, The evaluation of extrapyramidal disease. In: de Ajuriaguerra J, Gauthier G, eds. Monoamines noyaux gris centraux et syndrome de Parkinson. Paris: Masson and Cie 1971; 313-325

12. Overall JE, Gorham DR. The brief psychiatric rating scale. Psychological Reports 1962; 10: 799-812.

13. Folstein MF, Folstein SE, McHugh PR. "Mini-Mental State". A practical method for grading the cognitive state of patients for the clinician. J Psychiatr Res 1975; 12: 189-198.

14. Hoehn, MM, Yahr MD. Parkinsonism; onset, progression and mortality. Neurology 1967; 17: 427-442.

15. Nausieda PA, Weiner WJ, Kaplan LR, et al., Sleep disruption in the course of chronic levodopa therapy: An early feature of the levodopa psychosis. Clinical Neuropharmacol 1982; 5: 183-194.

16. Sacks OW, Kohl MS, Messeloff CR, et al. Effects of levodopa in parkinsonian patients with dementia. Neurology 1972; 22: 516-519.
17. Birkmayer W, Danielczyk W, Neumayer E, et al. Nucleus ruber and l-dopa psychosis: biochemical post-mortem findings. J Neural Transm 1974; 35: 93-116.

18. Birkmayer W, Danielczyk W, Neumayer E, et al. Dopaminergic supersensitivity in parkinsonism. In: Calne DB, Chase TN, Barbeau A, eds. Advances in Neurology. New York: Vol 9, Raven Press 1975; 121-129.

19. Nausieda PA, Tanner CM, Klawans HL. Serotonergically active agents in levodopa induced psychiatric toxicity. In: Fahn $\mathrm{S}$, Calne DB, Shoulson I, eds. Advances in Neurology. New York: Vol 37, Experimental Therapeutics of Movement Disorders, Raven Press 1983; 23-31.

20. Beasley BL, Nutt JG, Davenport RW, et al. Treatment with tryptophan of levodopa-associated psychiatric disturbances. Arch Neurol 1980; 37:155-156.

21. Moksovitz C, Moses H, Klawans HL. Levodopa-induced psychosis: A kindling phenomenon. Am J Psychiatry 1978; 135: 669-675.

22. Klawans HL, Crossett $P$, Dana N. Effect of chronic amphetamine exposure on stereotyped behaviour: Implications for pathogenesis of 1-dopa-induced dyskinesias. In: Calne DB, Chase TN, Barbeau A, eds. Advances in Neurology. New York: Raven Press $1975 ; 105-112$.

23. Klawans HL, Margolin D. Amphetamine-induced dopaminergic hypersensitivity in guinea pigs, implications in psychosis and human movement disorders. Arch Gen Psychiatry 1975; 32: 725-732.

24. Klawans HL, Goetz C, Nausieda PA, et al. Levodopa induced dopamine receptor hypersensitivity. Ann Neurol 1977;2: 125-129.

25. Nausieda PA, Weiner WJ, Kanapa DJ. Bromocriptine-induced behavioural hypersensitivity: Implications for the therapy of parkinsonism. Neurology 1978; 28: 1183-1188.

26. Scholz E, Dichgans J. Treatment of drug-induced exogenous psychosis in parkinsonism with clozapine and fluperlapine. Eur Arch Psychiatra Neurol Sci 1985; 235: 60-64.

27. Bischoff $S$. The hippocampus as a site of action for antipsychotic activity of neuroleptics. Experimentia 1985; 41: 1217.

28. Idänpään-Heikkilä J, Alhava E, Olkinuora M, et al. Agranulocytosis during treatment with clozapine. Europ J Clin Pharmacol 1977; 11:193-198.

29. Modigh K, Balldin J, Eriksson E, et al. Increased responsiveness of dopamine receptors after ECT - A review of experimental and clinical evidence. In: Lerer B, Weiner RD, Belmaker H, eds. ECT: Basic Mechanisms. London: John Libbey \& Co 1984; 18-27.

30. Balldin J, Edén S, Granérus A-K, et al. Electroconvulsive therapy in Parkinson's syndrome with "on-off" phenomena. J Neural Transm 1980; 47: 11-21.

31. Balldin J, Granérus A-K, Lindstedt G, et al. Predictors for improvement after electroconvulsive therapy in parkinsonian patients with on-off symptoms. J Neural Transm 1981; 52: 199-211.

32. Ward C, Stern GM, Pratt RTC, et al. Electroconvulsive Therapy in parkinsonian patients with the "on-off" syndrome. J Neural Transm 1980; 49: 133-135.

33. Lerer B., Jabotinsky-Rubin K, Bannet J, et al. Electroconvulsive shock prevents dopamine receptor supersensitivity. Eur J Pharmacol 1982; 80: 131-134. 